\title{
De/politisering van de Waarheid
}

Complottheorieën, alternatieve feiten en nepnieuws in het tijdperk van de postwaarheid

Jaron Harambam

SOC 13 (1): 73-92

DOI: 10.5117/SOC2017.1.HARA

\begin{abstract}
The Truth dominates many public discussions today. Conventional truths from established epistemic authorities about all sorts of issues, from climate change to terrorist attacks, are increasingly challenged by ordinary citizens and presidents alike. Many have therefore proclaimed that we have entered a post-truth era: a world in which objective facts are no longer relevant. Media and politics speak in alarmist discourse about how fake news, conspiracy theories and alternative facts threaten democratic societies by destabilizing the Truth - a clear sign of a moral panic. In this essay, I firstly explore what sociological changes have led to (so much commotion about) the alleged demise of the Truth. In contrast to the idea that we have moved beyond it, I argue that we are amidst public battles about the Truth: at stake is who gets to decide over that and why. I then discuss and criticize the dominant counter reaction (re-establishing the idea of one objective and irrefutable truth), which I see as an unsuccessful de-politisation strategy. Basing myself on research and experiments with epistemic democracy in the field of science studies, I end with a more effective and democratic alternative of how to deal with knowledge in the complex information landscape of today.
\end{abstract}

Het zal u niet ontgaan zijn. De Waarheid is de afgelopen tijd volop onderwerp van discussie en strijd geworden. Zo maken velen die de opwarming van de aarde met zorg bekijken zich druk over hen die tegen de breed aangenomen verklaring ingaan dat dit door menselijk handelen komt, terwijl anderen video's op het internet zien van architecten en ingenieurs die betogen dat de WTC-torens in New York onmogelijk door ingevlogen vliegtuigen ingestort kunnen zijn en hierna de straat op gaan om te protesteren 
tegen de hegemonie van het gangbare verhaal over de aanslagen van 9/11. En wie was niet gechoqueerd (of jaloers?) over het gemak waarmee Macedonische jongeren een goed zakgeldje verdienden met het online verspreiden van sensationele berichten die als waarheid worden gepresenteerd? Met de komst van Donald Trump als president van de Verenigde Staten is de discussie over de Waarheid alleen nog maar prominenter geworden. Want waar gaat het allemaal heen als de machtigste persoon van de wereld te pas en te onpas allerlei kritische geluiden en zelfs hele instituten zoals de gerespecteerde media als nер bestempelt? Van verschillende kanten wordt geroepen dat wij nu in het postwaarheid-tijdperk zijn beland, een wereld waarin objectieve feiten een steeds kleinere rol zouden spelen en emotionele of persoonlijke overtuigingen in toenemende mate als feitelijke waarheden gepresenteerd en gezien worden. ${ }^{1}$

Maar hoewel de media bol staan van berichten over hoe complottheorieën, alternatieve feiten en nepnieuws democratische samenlevingen in gevaar brengen door de Waarheid te ontwrichten, is het sociologisch gezien allerminst duidelijk wat hier nu precies aan de hand is. Ja, de waarheid lijkt meer gepolitiseerd dan ooit nu verschillende groepen mensen hier met hun eigen kennis een beroep op doen, maar hebben we nu ook echt te maken met een serieuze verandering van ons kennislandschap en de manieren waarop wij ons hierin bewegen? Of is de echte verandering vooral de opkomst van afschuw en paniek van de culturele, epistemische en politieke 'gevestigden' over het feit dat 'buitenstaanders' zich ineens zijn gaan bemoeien met de Waarheid (vgl. Elias en Scotson 1994)? De enorme publieke onrust over de alomtegenwoordigheid van allerlei onwaarheden in publieke debatten lijkt namelijk alle schijn te hebben van een morele paniek (Cohen 2002), maar het lijkt eveneens moeilijk te ontkennen dat de komst van het internet en sociale media geen fundamentele veranderingen te weeg heeft gebracht in de manieren waarop wij met kennis en met elkaar omgaan.

De kwestie die ik in dit essay centraal wil stellen is echter niet of er een morele paniek is, maar waar die paniek precies over gaat. Daarvoor is het noodzakelijk eerst beter in kaart te krijgen welke sociologische veranderingen ten grondslag liggen aan de opkomst van zo veel beroering over de zogenaamde teloorgang van de Waarheid. In tegenstelling tot het idee dat we ons niet meer tot de waarheid zouden verhouden maar er voorbij zijn, beargumenteer ik dat we juist middenin een publieke strijd om de Waarheid zitten. De kwestie die hierin centraal staat is wie mag bepalen wat waar is en waarom. Het dominante tegengeluid welke oplossingen zoekt in het in ere herstellen van de Waarheid zie ik echter als een onsuccesvolle 
depolitiseringstrategie. Kennis is namelijk niet transcendentaal en onomstotelijk, maar het product van bepaalde mensen in een bepaalde tijd en plaats. Na mijn sociologische kritiek op deze depolitiseringstrategie uiteengezet te hebben, zal ik dit essay eindigen met democratischere alternatieven voor hoe om te gaan met kennis in het huidige complexe informatielandschap.

\section{Vage begrippen, krachtige retorische wapens}

Voordat ik inga op de sociologische veranderingen die de maatschappelijke discussie over de Waarheid hebben doen ontbranden, wil ik eerst nog aanstippen hoe de in deze discussie centraal staande termen complottheorie, nepnieuws en postwaarheid allesbehalve vanzelfsprekend en neutraal zijn. Hoewel alle drie de termen op het eerste oog goed lijken te omschrijven waar ze naar moeten verwijzen, blijken ze empirisch gezien vooral ambigu, met normatieve assumpties verweven en een uitdrukking van macht te zijn. Zo is het met een letterlijke definitie allerminst mogelijk om de empirisch gemaakte onderscheidingen tussen wel/geen complottheorie of wel/geen nepnieuws te volgen. Wat als complottheorie of nepnieuws gezien wordt blijkt namelijk niet (enkel) uitdrukking te zijn van inhoudelijke eigenschappen, maar vooral van sociale situering: bepaalde vormen van kennis worden als onwaar bestempeld (Harambam 2017: 30; vgl. Bratich 2008: 3; Coady 2006: 3). Met dit klassieke labelingsperspectief komt de kwestie van macht centraal te staan (vgl. Becker 1963; Goffman 1963; Spector and Kitsuse 1977). Want wie mag bepalen wat het officiële verhaal, oftewel de Waarheid is? Wie is er in de positie om bepaalde vormen van kennis te diskwalificeren door het als complottheorie of nepnieuws te bestempelen? Het benoemen alleen al is dus een politisering. Daarnaast zit in de deze termen de assumptie ingebakken dat het onderscheid tussen nep en echt simpel en duidelijk te maken is. Maar wanneer sommige complottheorieën waar blijken te zijn (zoals de afluisterpraktijken van de NSA) en ander echtnieuws juist gefabriceerd blijkt te zijn (zoals de massavernietigingswapens in Irak), wat is dan eigenlijk echt en nep? Hetzelfde geldt voor postwaarheid, want leefden we eerder dan in een wereld waar niet gelogen en de waarheid niet verdraaid werd? Juist door de onbestemdheid van deze termen worden ze krachtige retorische wapens om allerlei ongewillige geluiden in maatschappelijke discussies simpel en snel te diskwalificeren (Harambam 2017; vgl. Bjerg en PresskornThygesen 2017; Husting en Orr 2007). Verschillende groepen mensen die 
tegen de heersende waarheden van media, wetenschap en politiek in gaan, zien hun argumenten in rook opgaan doordat het, al dan niet terecht, als complottheorie of nepnieuws bestempeld wordt. Nu Trump (en zijn aanhang) juist dezelfde termen weer gebruikt om de heersende waarheden van de mainstream media, wetenschap en politiek te diskwalificeren is de cirkel rond. Doordat deze termen lege, maar enorm krachtige retorische wapens zijn in publieke discussies rondom de Waarheid zijn ze eveneens zwaar gepolitiseerd.

\section{Wat is hier nou aan de hand? Omstreden instituties en kennis}

Een eerste verklaring voor de opkomst van zo veel maatschappelijke beroering over de zogenaamde teloorgang van de Waarheid ligt, zoals veel commentatoren beargumenteren, in het dalende vertrouwen in instituties, experts en hun kennis. Verschillende grootschalige onderzoeken van onder andere Gallup (2016) en Edelman (2017) laten zien dat publieke instituties als de media, politiek, overheid, het rechtssysteem en zo meer, in toenemende mate gewantrouwd worden. ${ }^{2}$ Natuurlijk kan men zich afvragen wat dit soort cijfers nu precies betekenen, er valt immers een hoop af te dingen op de botheid van de gebruikte vraagstellingen. Andere wetenschappers proberen dit daarom verder te onderzoeken en van meer betekenis en context te voorzien: wat betekent 'vertrouwen hebben in' eigenlijk, waar komt het tegenwoordige wantrouwen vandaan en wat zijn de gevolgen hiervan voor democratische samenlevingen (vgl. Gauchat 2011; Moy and Pfau 2000; Misztal 2013)?

Ook in mijn promotieonderzoek naar de wereld van complotdenkers komt dit wantrouwen naar instituties, zoals de media, wetenschap en overheid sterk naar voren. Deze mensen beargumenteren om verschillende redenen, en vaak met grote nauwkeurigheid, dat deze instituties niet langer werken zoals ze bedoeld zijn omdat een elite deze beheerst en voor eigen gewin inzet (Harambam 2017). Naast dit ongenoegen over het functioneren van onze instituties, wantrouwen complotdenkers ook de kennis die zij produceren. Deze zijn volgens hen helemaal niet zo objectief en onomstotelijk als beweerd wordt: feiten worden volgens (sommige) complotdenkers actief geconstrueerd en zijn altijd het product van bepaalde mensen in een bepaalde tijd en plaats (Harambam en Aupers 2015). Dat deze experts die feiten mogen en kunnen produceren onderdeel zijn van een groep mensen met dezelfde afkomst en overtuigingen, een culturele 
elite, welke in hun ogen innig verbonden is met andere machtige netwerken in onze samenlevingen maakt dat dit wantrouwen naar hun kennis zo groot is (vgl. Achterberg et al. 2017; Lukkassen 2015).

De empirische manifestaties van dit wantrouwen naar gevestigde instituten en hun kennis zijn duidelijk zichtbaar in verschillende publieke discussies. Een concreet voorbeeld was te zien in een onlangs uitgezonden aflevering van het NPO-televisieprogramma De Stelling, waarin 'mensen uit alle lagen van de samenleving met elkaar in debat gaan over de heikele thema's van vandaag' ${ }^{3}$ - een vurige wens van NPO-bestuursvoorzitter Shula Rijxman die na de overwinning van Trump vond dat onze media het volk beter moet horen. In deze uitzending kwamen de feiten van onafhankelijke kennisinstituten sterk onder vuur te liggen. Verschillende mensen hekelden de officiële cijfers van het CBS en SCP omdat die 'op de hand zouden zijn van de regering' en niet zouden stroken met hun eigen beleving in het dagelijks leven, een argument dat eveneens sterk terugkwam in mijn eigen onderzoek (Harambam en Aupers 2017). Deze publieke strijd om de feiten, om de Waarheid, zien we natuurlijk net zo goed in de Verenigde Staten, waar Trump en zijn entourage de liberale en culturele elites opschrikten met de introductie van de orwelliaans aandoende term alternative facts. De (terechte) verontwaardiging en woede waren alomtegenwoordig, maar wat het vooral laat zien is dat de Waarheid simpelweg niet meer vanzelfsprekend is en van alle kanten bestreden wordt.

\section{Wat is hier nou aan de hand? Een veranderend informatielandschap}

Een tweede grote verklaring die vaak aangevoerd wordt voor de alomtegenwoordigheid van allerlei 'onwaarheden' in huidige publieke debatten is het veranderende informatielandschap. Waar de traditionele media vroeger een monopolie hadden op informatievoorziening, is dat met de komst van het internet drastisch veranderd. Iedereen kan tegenwoordig namelijk (nieuws)websites beginnen, blogs onderhouden of via sociale media aan live journalism doen. Doordat de traditionele media hun poortwachtersfunctie verliezen zou het internet onze informatievoorziening radicaal democratiseren: de gewone mens is nu 'in control' (Shapiro 1999, vgl. Jenkins 2006; Weinberger 2008). Alles wat vroeger door de traditionele media bewust en onbewust werd tegengehouden, vindt nu zonder problemen zijn weg naar geïnteresseerde publieken. Hierin schuilt natuurlijk een enorm democratisch potentieel: kritische, contrahegemonische en andere revolu- 
tionaire geluiden zijn ineens veel makkelijker te vinden en te verspreiden. Het internet krijgt hierdoor vaak messianistische krachten toebedeeld: de gewone mens zou verlost worden van de informatieketenen die haar tot dan toe klein hielden. Alle kennis is er ineens voor iedereen. Deze mening wordt door veel complotdenkers gedeeld, zo merkte ik tijdens mijn onderzoek. Het internet is voor hen de vrijplaats waar machthebbers geen invloed hebben en zij ongestoord allerlei geheime en verborgen gehouden informatie kunnen verzamelen en delen (Harambam 2017).

Maar voor veel mensen laat die de utopische democratiseringsbelofte van het internet zich nu van zijn andere kant zien. Iedereen kan zich tegenwoordig als expert voordoen op het internet, en allerlei pseudowetenschappelijke kennis (of erger) kan op gelikte en professioneel uitziende sites als betrouwbaar en waarachtig worden gepresenteerd. Daarnaast zou de informatie die er is ook nog eens minder van kwaliteit zijn geworden omdat nieuwsaanbieders moeten concurreren om aandacht en hierdoor meer sensationele berichten, oftewel clickbait, zouden produceren. Bovendien zouden wij door de overvloed aan informatie op het internet lijden aan een information overload: er is té veel informatie beschikbaar om door ons zinnig verwerkt te kunnen worden (Shenk 1998). In plaats van kennisverhogend, zou het internet hierdoor juist kennisverlagend zijn: we kunnen steeds slechter onderscheid maken tussen kwalitatief goede kennis en meer onzinnige informatie (Kovach 2011).

Het gevolg van deze informatieovervloed is dat we vooral informatie zouden binnenkrijgen die onze bestaande ideeën en wereldbeelden bevestigen, en tegenstrijdige kennis moedwillig en onbewust zouden negeren. Deze psychologische eigenschap, ook wel confirmatiebias of cognitieve dissonantie genoemd, wordt nog eens versterkt door nieuwe technologische ontwikkelingen. Zoek- en selectiealgoritmes structureren onze informatievoorziening op basis van eerder vertoond gedrag (denk aan Google en de gepersonaliseerde zoekresultaten die wij krijgen), of op basis van wat onze peers lezen en leuk vinden (denk aan Facebook en hoe zij onze Newsfeed opmaken) (Van Dijck et al. 2016). Het effect hiervan zou zijn dat we te weten komen wat we eigenlijk al wisten, en geen andere meningen horen dan die we reeds al hoorden. Oftewel, we zouden gevangen zitten in zogenoemde filter bubbles (Pariser 2011) en zouden enkel zelfbevestigende verhalen aanhoren in zogenoemde echo chambers (Jamieson en Capella 2008). Daarbij zijn deze algoritmes ook nog eens goed bewaarde bedrijfsgeheimen, waardoor we niet eens weten hoe ze precies werken en op basis van welke criteria onze informatiewinning gestructureerd is (Van Dijck et al. 2016; Morozov 2011). Het is fascinerend om te zien hoe psychologische 
eigenschappen hier dus ogenschijnlijk onfortuinlijk samensmelten met de sociologische neiging om gelijkgestemden op te zoeken en met technologische ontwikkelingen die de wereld die wij te zien krijgen vanuit bedrijfseconomische belangen sterk filteren op onze bestaande voorkeuren.

Daarbij komt dat internationale actoren zich, door het mondiale en open karakter van het huidige informatielandschap, in toenemende mate kunnen mengen in nationale publieke discussies, wat dit probleem een geopolitieke zaak maakt. Zo schijnt Rusland allerlei nationale publieke debatten te beïnvloeden (denk aan Black Lives Matter, Brexit, de MH17ramp, de Europese migratiecrisis, de Catalaanse onafhankelijkheidsstrijd etc.) door het online verspreiden van propaganda (voornamelijk) in de vorm van disinformatie (onder andere) verspreid door trollen en bots met het doel om maatschappelijke verdeeldheid te zaaien en democratische waarden en instituties te destabiliseren (vgl. Aro 2016; Goble 2014; Kelly et al. 2017). Deze nieuwe vorm van geopolitieke oorlogsvoering, een inverse (of perverse) maar uiterst effectieve vorm van soft power (Nye 2004), is mogelijk geworden in dit nieuwe informatielandschap waarbij de publieke opinie op geraffineerde en deels geautomatiseerde wijze gestuurd en gemanipuleerd kan worden.

Ogenschijnlijk onzichtbare actoren kunnen door het inzetten van bots (zelfsturende softwareapplicaties die zich voordoen als echte socialemediaaccounts en met hoge snelheid (nep)berichten versturen, retweeten, liken en verder verspreiden) bepaalde ideeën de wereld in helpen en bevorderen (een duidelijk voorbeeld van de agency van wat Latour non-humans noemt (2004)). Die bots kunnen ook nog eens aan elkaar gekoppeld worden waardoor zogenoemde botnets ontstaan: enorm krachtige en zelf versterkende netwerken die hun eigen berichten promoten. Deze botnets zijn perfect aangepast aan de mechanismes van socialemediaplatformen welke de activiteiten van botnets als trending topics zien en deze belangrijker in hun feeds laten worden. De algoritmes van deze platformen laten menselijke gebruikers hierdoor denken dat het belangrijke onderwerpen zijn waar veel mensen over discussiëren of voor- of tegenstander van zijn - denk aan maatschappelijke zorgen over instromende migranten. Traditionele media pakken dit weer op, en zo wordt via technologische mechanismes een self-fulfilling information prophecy gecreëerd. Als een onderwerp op een gegeven moment genoeg aandacht krijgt op de sociale media, ook al is dat een artificieel gecreëerde en valse voorstelling van zaken, dan kan dat momentum zich razendsnel uitbreiden tot een daadwerkelijke situatie waarbij dat onderwerp reëel is geworden en mensen hiernaar gaan handelen. De publie- 
ke beïnvloeding lijkt in dit nieuwe informatielandschap kinderspel geworden.

Paniek alom dus, want als goede informatie ongrijpbaar wordt, komt de democratie in gevaar. Vanuit verschillende politiek-filosofische tradities wordt gesteld dat een autonome en transparante informatiewinning en de mogelijkheid om tegenstrijdige geluiden te kunnen aanhoren van cruciaal belang zijn voor een goed functionerende democratie (zie Dewey 2004; Habermas 1991; Mouffe 2000; Nussbaum 2016). Hoewel denkers uit de verschillende tradities van mening verschillen over hoe onenigheid aangesproken en opgelost moet worden, staat het idee van waarheidsvinding door de uitwisseling of botsing van ideeën bij allen centraal. De hierboven beschreven situatie van het hedendaagse informatielandschap laat daar volgens deze denkers totaal geen ruimte toe omdat we ons dus niet goed kunnen informeren, we moeilijk met andersdenkenden in contact komen en we gemakkelijk voor de gek gehouden kunnen worden. Dit ondermijnt volgens hen niet alleen het publieke debat, maar leidt ook tot sterke polarisatie in de samenleving en parallelle leefwerelden (zie Sunstein 2017) en maakt ons kwetsbaar voor manipulatie en propaganda (zie Morozov 2011; Pariser 2011; Tufekci 2017b).

Socialemediaplatformen als Facebook, Youtube en Twitter worden daardoor steeds meer op het matje geroepen over hun rol in het faciliteren van propaganda en het bevorderen van maatschappelijke tegenstellingen. In tegenstelling tot hun claim dat zij slechts mensen en ideeën met elkaar in contact brengen op basis van hun eigen voorkeuren, vinden velen dat deze depolitiseringstrategie niet langer houdbaar is aangezien de platformen wel degelijk bepaalde verhalen prioriteren en hierdoor dus niet zo neutraal zijn als ze zeggen (zie Van Dijck et al. 2016; Dojcinovic 2017; Gane 2017; Tufekci 2017a).

De eerdergenoemde complexe versmelting van psychologische, sociologische en technologische eigenschappen wordt dus nog eens verder gecompliceerd door de diverse bedrijfs-, geopolitieke en maatschappelijke belangen die hiermee verwikkeld zijn. De alomtegenwoordigheid van allerlei (on)waarheden lijkt daardoor een zogenoemd wicked problem geworden: een probleem met een enorme complexiteit door de aanwezigheid van verschillende, op elkaar inspelende en continue veranderende factoren waarbij schijnbare oplossingen steeds weer tot andere problemen leiden (vgl. Brown et al. 2010; Kolko 2012; Rittel en Webber 1973). De weg uit dit moeras van (on)waarheden lijkt hierdoor moeilijk te vinden en de noodzaak van betrouwbare en goede informatie groter dan ooit. 


\section{4 'Dit is een appel'. Depolitisering van de Waarheid als oplossing?}

$\mathrm{Nu}$ is er nog wel wat af te dingen op de analyse dat wij door deze veranderingen in het informatielandschap inderdaad enkel onze eigen wereldbeelden te zien krijgen en hierdoor een makkelijk prooi voor massale propaganda zijn. Auteurs als Morozov (2011), Pariser (2011) en Sunstein (2017) maken, hoewel goed geïnformeerd, toch meer anekdotisch en theoretisch hun punt. Meer systematische en empirische onderzoeken zijn nodig om deze ideeën daadwerkelijk te staven. Gelukkig is een begin reeds gemaakt (zie voor een aardig overzicht: Mortimer 2017). Maar meer dan zulke analyses bekritiseren wil ik vooral ingaan op het dominante discours van waaruit oplossingen gezocht worden voor deze informatiecrisis, namelijk een positivistisch ideaal waarin feiten objectief en vaststaand zijn, waar naar experts geluisterd moet worden, en waar de Waarheid niet alleen heilig is, maar vooral ook gedepolitiseerd wordt.

Zo zijn grote mediabedrijven als CNN en The New York Times grootschalige mediacampagnes gestart tegen fake news en alternative facts, waarin het beeld geschetst wordt dat er slechts één uniforme waarheid kan zijn. CNN heeft een filmpje gemaakt waar ze een appel laten zien, en vervolgens zeggen: 'This is an apple... Some people might try to tell you that it's a banana. They might scream banana, banana, banana over and over and over again. They put BANANA in all caps. You might even start to believe that this is a banana. But it's not. This... is an apple.' Het filmpje eindigt met 'Facts First. CNN'. ${ }^{4}$ Onze wereld is helemaal niet zo complex, stelt CNN, feiten spreken voor zich, en daar is eigenlijk geen discussie over nodig; een appel is immers een appel, toch? De NYT laat een complexer beeld zien, hun filmpje start met een opeenvolging van verschillende varianten van 'the truth is...': 'the truth is our nation is more divided than ever', 'the truth is alternative facts are lies', 'the truth is the media is dishonest'. En na een versnelling en kakofonie van allerlei verschillende waarheidsclaims over sociale, morele en politieke zaken, komt het tot een climax waar het beeld weer tot rust komt en gesteld wordt dat 'the truth is hard... to find... to know... The truth is more important now than ever. The New York Times'. ${ }^{5}$ Ondanks de grotere nuance blijft het idee centraal staan van de Waarheid als uniform en objectief ideaal, welke, met veel moeite weliswaar, toch gevonden kan worden. Ook in Nederland hoor je dit soort positivistische geluiden die een simplistisch idee van waarheid propageren. Zo heeft het NRC Handelsblad een code opgesteld waarin zij hun journalistiek uitleggen en hierin een hard onderscheid maken tussen 
nieuws en opinie, feiten en commentaar: 'Onze journalistiek draait om waarheidsvinding en, op basis daarvan, meningsvorming [...] Wij hanteren een scheiding tussen feiten en commentaar (facts are sacred, comment is free). In de berichtgeving staan feiten centraal (en de context daarvan in duiding en analyse), niet de mening of persoonlijke voorkeur van de auteur. In opinies gaat het om persoonlijke standpunten'. ${ }^{6}$ Het dominante antwoord is er dus één van harder roepen dat de Waarheid in ere hersteld moet worden door feiten en meningen strikt van elkaar te scheiden.

Vaak wordt de schuld van de informatiecrisis gelegd bij het postmodernisme dat de intellectuele basis zou hebben gelegd voor het ontkennen van de Waarheid zoals dat nu door Trump en verwante figuren gebeurt. Zo stelt wetenschapsfilosoof Maarten Boudry in een recent stuk in het NRC Handelsblad dat hoewel 'de ideologie van het postmodernisme mijlenver verwijderd [is] van die van Trump, het intellectuele vandalisme van concepten als "waarheid" en "feit" gelijksoortig [is]. De wapens die we nodig hebben tegen de populistische feitenvrijheid heeft het postmodernisme ons afhandig gemaakt. ${ }^{7}$ Evengoed stelt filosoof en psycholoog Kees Kraaijenveld in zijn 'pleidooi voor de waarheid' dat 'er talloze ideologische stromingen [zijn] die aan de waarheid een broertje dood hebben. Denk aan pragmatisme, het postmodernisme of het sociaal-constructivisme'. Hij roept dan ook op om 'de waarheid [te] verdedigen tegen relativisme [...] Niet iedere mening telt. Niet iedere zienswijze is even waar en daarmee even waardevol $[\ldots]$ We moeten waarheid weer als waarde omarmen [en] meer waarde hechten aan wat experts zeggen dan aan wat leken roepen'. De intellectuele oorsprong van het postwaarheidtijdperk moeten we volgens hem dus vinden in het postmodernisme, of het daarmee verbonden relativisme. Zelfs Bruno Latour, vaak (verkeerd) aangehaald als archetypische postmodernist, krabt zich achter de oren nu 'the weapons of social critique [are] taken away from us by the worst possible fellows as an argument against the things we cherish' (2004: 227). Hij vraagt zich in dat interessante stuk bezorgd af of het constructivisme en het analytische gereedschap dat deze traditie ontwikkeld heeft nog wel voldoet nu 'voldongen feiten' zoals de klimaatverandering op eenzelfde manier gedeconstrueerd en ontkracht worden?

$\mathrm{Nu}$ Trump en consorten allerhande waarheden ontkrachten en als nep bestempelen, zijn meer wetenschappers binnen de Science and Technology Studies (STS) zich gaan afvragen of zij inderdaad niet verantwoordelijk zijn voor dit postwaarheidtijdperk waar alle feiten zonder veel moeite in twijfel getrokken kunnen worden (Collins et al. 2017; Lynch 2017; Fuller 2016a, 2016b, 2017; Sismondo 2017). Zo beargumenteren Collins et al. dat '[STS's] 
logic of symmetry, and the democratizing of science it spawned, invites exactly the scepticism about experts and other elites that now dominates political debate' (2017: 580) en dat '[t] he views STS was espousing were consistent with post-truth irrespective of their authors' intentions or their causal impact' (ibid.: 581). Fuller stelt langs dezelfde lijn dat de 'post-truth world is the inevitable outcome of greater epistemic democracy' (2016a) en dat het daarom 'most puzzling' is dat 'STS recoils from these tropes whenever such politically undesirable elements as climate change deniers or creationists appropriate them effectively for their own purposes' (2017). Waar deze STS-wetenschappers Latour en Sismondo van beschuldigen is dat zij wetenschap (en dus feiten) weer proberen te depolitiseren, terwijl zij als STS'ers nu juist zo hardnekkig hebben aangetoond dat wetenschappelijke feiten, en dus de Waarheid, nogal wat politiek werk omvat om het als zodanig de wereld in te krijgen en te houden (Collins et al. 2017; Lynch 2017; Fuller 2016b, 2017).

De Waarheid depolitiseren, zoals het eerder besproken dominante antwoord op de huidige informatiecrisis, is naar mijn idee daarom slechts een schijnoplossing die zowel niet klopt als niet effectief is. Het klopt niet omdat een grote traditie van wetenschapssociologen en antropologen met empirisch gedegen onderzoek heeft laten zien dat wetenschappelijke feiten geen simpele reflecties zijn van de wereld zoals die is, maar het product zijn van een breed netwerk van onderzoekspraktijken, validatiestructuren, professionele netwerken en politieke dynamieken die deze waarheden in het leven roepen en houden (zie Gieryn 1999; Latour 1987). Dit maakt deze kennis niet minder waar, maar wel het product van menselijk handelen (in interactie met objecten). De tegenstelling die door eerdergenoemde positivistische waarheidsridders wordt gemaakt waarbij constructivistische kritieken op een vaststaande en objectieve waarheid worden weggezet als een postmodern relativisme waarin alle vormen van kennis aan elkaar gelijk zouden worden is een valse. Het zou er bij de waardering van kennis niet om moeten gaan of iets waar is of niet, maar hoe deze is opgebouwd, uit welke kennisbronnen zij putten en welke sociomateriële netwerken en infrastructuren deze ondersteunen. Waarheid laat zich naar mijn idee beter kennen als continuüm (meer-minder waar), of eigenlijk nog beter als multipel ${ }^{9}$ (Mol 2002), dan als een dichotomie (waar/ onwaar).

Daarnaast is de Waarheid depolitiseren niet effectief omdat veel mensen simpelweg niet langer in een transcendente, objectieve en vaststaande waarheid geloven. Zij benadrukken juist een politisering van de Waarheid: 'er zijn geen objectieve feiten, dit is jullie waarheid, niet de onze' is het 
geluid dat je hoort uit de hoek van vele populisten (en hun aanhang). Maar ook is het voor velen veel aannemelijker geworden dat er verschillende waarheden naast elkaar kunnen bestaan. Zo laat ik in mijn proefschrift naar complotdenkers zien dat zij, bijvoorbeeld door het reizen en wonen in andere werelddelen, ontdekken dat hun waarheid over bepaalde wereldgebeurtenissen helemaal niet de enige of echte waarheid hoeft te zijn (Harambam 2017: 167-170). Ten slotte heeft men ook steeds meer wetenschappelijke kennis over hoe de Waarheid werkt. Zo worden constructivistische argumenten over kennisproductie en de rol van experts en leken hierin nu gebruikt door verschillende groepen mensen (bijvoorbeeld zieken, religieuzen, anti-vaccinatiebewegingen) die aanspraak proberen te maken op epistemische autoriteit (zie Arksey 1998; Epstein 1996; Fuller 2008; Martin 1996, 2017) - een duidelijk voorbeeld van de democratisering van wetenschappelijke kennis.

Hoewel het begrijpelijk is dat gerespecteerde mediabedrijven zich verzetten tegen de geluiden die hun journalistiek weg zetten als nepnieuws en dat constructivistische wetenschappers zich zorgen maken over het gebruik van hun analytische gereedschap voor politieke doeleinden waar zij niet achter staan, is het depolitiseren van de Waarheid dus geen doeltreffend antwoord op de huidige postwaarheidsituatie omdat veel mensen simpelweg iets anders willen horen dan deze metafysische, want geblackboxte, beroepen op de waarheid. De oproepen van eerdergenoemde waarheidsridders beginnen daarom steeds meer te lijken op de wanhoopskreten van priesters in de jaren zestig die gods woord hoog probeerden te houden, terwijl de kerken massaal leegstroomden. Maar in plaats van al dan niet terecht de schuld voor het postwaarheidtijdperk te leggen bij het constructivisme van STS, wil ik hier beargumenteren dat STS juist een oplossing voor deze culturele situatie van epistemische instabiliteit kan bieden (Harambam 2017).

\section{$5 \quad$ Inzicht en inspraak. Een constructivistisch en democratisch alternatief}

Om een epistemologisch sterke en sociologisch effectieve manier te ontwikkelen waarmee in een gedigitaliseerd postwaarheidtijdperk met kennis omgegaan kan worden, leun ik sterk op twee belangrijke principes van STS die ik hier bijeenraap en inzicht en inspraak noem (vgl. Hackett et al. 2008; Sismondo 2004). Een belangrijke prestatie van deze wetenschappelijke traditie is dat die met empirisch gedegen onderzoek heeft laten zien hoe 
wetenschappelijke feiten geproduceerd worden. STS heeft hiermee inzicht gegeven in de verschillende socio-materiele factoren die een rol spelen bij het in leven roepen en houden van wetenschappelijke kennis (vgl. Haraway 1991; M'charek et al. 2015; Mol 2002; Latour 1987; Lynch 1997). Het symmetrieprincipe waarbij zowel gevestigde (wat we nu voor waar aannemen) als uitdagende (wat toen of nu tegen het gevestigde idee in ging) vormen van kennis op eenzelfde manier geanalyseerd zouden moeten worden hangt hier sterk mee samen (Bloor 1991). Daarnaast is het promoten van inclusie van gemarginaliseerde groepen en hun expertise in kennisproductie, ook wel epistemische democratie genoemd, een belangrijke pijler in het alternatief dat ik voorstel (vgl. Collins en Evans 2008; Holst en Molander 2014; Maasen en Weingart 2006).

In tegenstelling tot het idee dat kritiek op het geloof in de Waarheid zou leiden tot een relativistische wereld waarin alle vormen van kennis aan elkaar gelijk zouden zijn, bepleit ik juist dat het openbreken van de black box waarmee (wetenschappelijke) feiten gewoonlijk worden gepresenteerd, het mogelijk maakt om onderscheid te kunnen maken tussen kwalitatief goede en minder goede kennis. Met behulp van empirisch navolgbare verslagleggingen over hoe bepaalde feiten en waarheden tot stand zijn gekomen, kan er inhoudelijk gesproken worden over waarom deze vorm van kennis beter is dan een andere, en dat zonder te hoeven leunen op een blind vertrouwen in experts en op de heersende waarheid. Transparantie over het productieproces en navolgbaarheid in plaats van objectiviteit als ideaal nastreven is essentieel voor het openlijk kunnen waarderen van kennis. De vraag die nu opdoemt is natuurlijk door wie hierover gesproken mag worden, en volgens welke regels. Tot nu toe was dit recht vooral voorbehouden aan wetenschappers zelf, die ondanks druk van buitenaf, intern bepalen wat goede kennis is en volgens welke procedures dat bepaald wordt (zie Gieryn 1999; Shapin 1994). Dit principe kan echter makkelijk leiden tot dogmatiek en autoritarisme ('wij hebben de waarheid in pacht'), hetgeen de kwaliteit van kennis niet ten goede komt, en tot meer maatschappelijke vervreemding ('wetenschap is ook maar een mening/linkse hobby'), hetgeen de publieke status van de wetenschap niet ten goede komt.

Net zoals verschillende STS-studies hebben laten zien dat het goed mogelijk is om verschillende maatschappelijke groepen te betrekken bij kennisproductieprocessen (zie Arksey 1998; Epstein 1996; Rabeharisoa et al. 2014), zo denk ik dat het net zo goed mogelijk moet zijn om verschillende groepen burgers te betrekken en inspraak te geven bij bepalingen van criteria en procedures voor goede kennis. Ik denk dan aan een soort 
burgerplatform dat in samenwerking met wetenschappers gesprekken voert, ideeën ontwikkelt en deze praktisch vorm gaat geven in een soort wetenschapswaakhond. De confrontatie van verschillende ideeën over criteria en procedures voor goede kennis moet zo tot een - altijd voorlopige uitkomst leiden waarbij verschillende maatschappelijke belangen gehoord en geactiveerd zijn. Dit is geen betoog voor een wetenschappelijk populisme waar de agenda door de massa bepaald wordt, maar wel een oproep om meer inzicht en inspraak te geven in de manieren waarop wij de kwaliteit van kennis evalueren en waarderen. Hoe dit burgerplatform er precies uit moet komen te zien (universeel of specifiek op onderwerpen afgestemd), welke samenstelling het moet hebben (hoe en wie selecteer je) en hoe dit georganiseerd en gefinancierd moet worden, zijn allemaal zaken die in de publieke discussie hierover besproken moeten worden.

Terugkomend op het onderwerp van dit essay, nepnieuws en postwaarheid, bepleit ik eenzelfde nadruk op meer inzicht en inspraak. Een eerste aanzet hiervoor is eigenlijk al gegeven door de wereldwijde opkomst van vele min of meer onafhankelijke factcheckers die verschillende claims op de Waarheid in publieke (on- en offline) debatten op juistheid controleren. ${ }^{10}$ Hoewel er discussie is over de mogelijkheid van het neutraal controleren van feiten, omdat die altijd ingebed zijn in grotere structuren van betekenisgeving (zie Uscinksi en Butler 2013), laten de empirische praktijken van factcheckers de genealogie van allerlei uitspraken in publieke debatten goed zien (Graves 2016). Hiermee wordt inzichtelijk gemaakt waar zulke uitspraken vandaan komen, hoe die in hun levensloop getransformeerd zijn en welke actoren hier een rol in hebben gehad. Dit inzicht is, net als transparantie over hoe wetenschappelijke feiten de wereld in worden geholpen, van groot belang in het openlijk kunnen waarderen van de vele waarheidsclaims die wij gepresenteerd krijgen. Inzicht alleen is echter geen panacee. De onafhankelijkheid van factcheckers wordt namelijk vaak in twijfel getrokken, bijvoorbeeld omdat ze te links zouden zijn. ${ }^{11}$ Hierdoor wordt al hun arbeid weer teniet gedaan, ze worden immers niet gelezen of geloofd. Omdat factcheckers veelal vanuit dezelfde culturele klasse afkomstig zijn, en veel 'gewone' mensen zich niet gezien en erkend voelen in publieke debatten en instituten (vgl. Hochschild 2016; Mepschen 2016; Kemmers 2017) lijkt mij inspraak in de vorm van vertegenwoordiging een manier om dit tegen te gaan. Ik stel daarom weer een burgerplatform voor, ditmaal van factcheckers, waarvan verschillende maatschappelijke groepen deel uit maken. Hierdoor zal deze praktijk evenwichtiger zijn en meer legitimiteit genieten.

Evengoed denk ik dat er meer inzicht en inspraak moet komen in de 
technologieën die onze informatievoorziening structureren. Hoewel het onwaarschijnlijk lijkt dat de grote techbedrijven hun goed bewaarde bedrijfsgeheimen over hoe hun algoritmes precies werken zullen gaan blootgeven (vgl. Foer 2017), valt er nog wel veel te winnen in het kweken van bewustwording over hoe algoritmes meer algemeen werken. Zo laten Eslami et al. (2015) zien dat gebruikers van sociale platformen grotendeels onbekend zijn met algoritmische beïnvloeding van hun informatievoorziening, maar dat meer bewustwording hierover wel leidt tot een actievere houding en een groter gevoel van agency ten opzichte van algoritmes, door deze bijvoorbeeld aan te passen aan meer persoonlijke wensen. Hoewel deze bevindingen steeds breder ondersteund worden (vgl. Bucher 2017; Dietvorst et al. 2015; Powers 2017), is het de vraag in hoeverre aanpassing van bedrijfsalgoritmes genoeg agency en privacy zullen geven om van een vrije en meer transparante informatiewinning te kunnen spreken. Er zijn daarom steeds meer initiatieven gekomen die meer onafhankelijke algoritmes willen ontwikkelen die in het belang van de gebruiker of van een bepaalde publieke waarde zoals diversiteit opereren (vgl. Diakopoulos 2016; Helberger et al. 2018). Zo hebben onderzoekers van het MIT Media Lab onder leiding van Ethan Zuckerman gewerkt aan Gobo, een socialemedia-algoritme met filters waar wij zelf, en niet een van die techbedrijven, controle over hebben. ${ }^{12}$ Met Gobo, zo stellen zij, kan je zelf bepalen wie of wat er in je nieuwsfeed komt, zelfs als dat nieuws of berichten zijn die juist van buiten je eigen leefwereld komen. Daarnaast is Gobo transparant over waarom elk item in je nieuwsfeed gekomen is, en wat je precies gemist hebt door jouw eigen filterkeuzes. Een geweldig idee, en hopelijk krijgen dit soort projecten meer en meer momentum, waardoor ze, als zelflerende systemen, beter en beter worden.

Het moge duidelijk zijn dat dit essay slechts een aanzet is tot meer wetenschappelijke en publieke discussie over hoe we op een andere manier om kunnen gaan met de complexe situatie van de alomtegenwoordigheid van allerlei (on)waarheden in het huidige informatielandschap. Meer inzicht en inspraak krijgen over wat wij als goede kennis zien en waarom lijken mij epistemologisch sterker en sociologisch effectiever dan een leeg beroep op de Waarheid en een daarmee samenhangend blind vertrouwen in experts. Ik kan hier nog geen volledig uitgewerkte plannen aanbieden over hoe we dit precies moeten vormgeven en welke actoren hierin mee zouden moeten beslissen, maar dat lijkt mij ook meer iets om samen te gaan bepalen. De uitdaging is om niet in technocratisme noch in wetenschappelijk populisme te vervallen. We kunnen daarbij goed gebruik maken van het werk van verschillende STS'ers die precies op dit snijvlak 
van wetenschap, technologie en politiek ideeën hebben ontwikkeld om dit soort complexe vraagstukken en de besluitvorming hierover te organiseren (zie Callon et al. 2009; Dijstelbloem 2008; Latour 2004; Latour en Weibel 2005; Marres 2012). Als wij democratie hoog willen houden, en niet overgeleverd willen zijn aan de macht van grote (tech)bedrijven en natiestaten die ons met nieuwe technologieën en aloude manipulatietechnieken kunnen laten dwalen in oerwouden van (mis)informatie, dan zullen wij deze discussies over hoe wij een vrij en sterk informatielandschap kunnen waarborgen meer moeten gaan voeren.

\section{Noten}

1. https://en.oxforddictionaries.com/word-of-the-year/word-of-the-year-2016.

2. http://news.gallup.com/poll/192581/americans-confidence-institutions-stays-low.aspx, https://www.edelman.com/trust2017/.

3. https://www.npo.nl/de-stelling-van-nederland/25-10-2017/AT_2090721.

4. https://www.youtube.com/watch?v=vckz6EAnzoY.

5. https://www.youtube.com/watch?v=gYoFdz350GE.

6. https://www.nrc.nl/static/front/pdf/NRC\%2oGedragscode\%2oHR\%2o(oo6).pdf.

7. https://www.nrc.nl/nieuws/2017/10/27/linkse-feitenvrije-wetenschap-ging-aan-trumpvooraf-a1578932

8. https://www.argumentenfabriek.nl/media/2477/pleidooi-voor-de-waarheid-kees-kraaijeveld-2016.pdf.

9. Maar op een gegeven moment moeten er toch keuzes gemaakt worden over welke waarheid in welke situatie gekozen wordt, en dan is hiërarchisering van de verschillende waarheden toch onvermijdelijk.

10. Zo heb je in de Verenigde Staten Factcheck.org (verbonden aan Annenberg School for Communication van de University of Pennsylvania), PolitiFact (verbonden aan de Tampa Bay Times en de Ford Foundation en het Democracy Fund) en The Fact Checker van de Washington Post. In Europa beginnen dit soort initiatieven nu ook vorm te krijgen: zo kent het Verenigd Koninkrijk het onafhankelijke Full Fact en Frankrijk heb je Les Décodeurs van Le Monde. In Nederland hebben we nog niet dit soort onafhankelijke organisaties die dit actief doen, wel hebben De Volkskrant en het NRC Handelsblad gespecialiseerde factcheckrubrieken, en zijn studenten van bijvoorbeeld de Universiteit Leiden hiermee actief (nieuwscheckers.nl). Zie voor een goed overzicht van al deze initiatieven en meer duiding het volgende artikel: http://nieuwejournalistiek.nl/factchecken/2017/02/01/strijd-om-het-feit-de-opkomst-van-factcheckers-binnen-en-buitende-journalistiek/.

11. Deze discussie over de politieke kleur van factcheckers zie je eveneens over politieke voorkeuren in de wetenschap: https://www.nrc.nl/nieuws/2017/og/o7/duisenberg-wilonderzoek-naar-de-politieke-kleur-van-universitaire-medewerkers-12863243-a1572495 of Inbar en Lammers (2012).

12. https://medium.com/@EthanZ/who-filters-your-news-why-we-built-gobo-socialbfa6748b594. 


\section{Literatuur}

Achterberg, P., W. de Koster en J. van der Waal (2017) A science confidence gap: Education, trust in scientific methods, and trust in scientific institutions in the United States, 2014. Public Understanding of Science, 26(6): 704-720, DOI: 0963662515617367.

Arksey, H. (1998) RSI and the experts: The construction of medical knowledge. London: University College London Press.

Aro, J. (2016) The cyberspace war: propaganda and trolling as warfare tools. European View, 15(1): 121-132.

Becker, H.S. (1963) Outsiders: Studies in the Sociology of Deviance. New York: The Free Press.

Bjerg, O. en T. Presskorn-Thygesen (2017) Conspiracy Theory: Truth Claim or Language Game? Theory, Culture \& Society, 34(1): 137-159.

Bloor, D. (1991[1976]) Knowledge and Social Imagery. Chicago: University of Chicago Press.

Bratich, J.Z. (2008) Conspiracy Panics: Political Rationality and Popular Culture. Albany: State of New York University Press.

Brown, V.A., J.A. Harris en J.Y. Russell (red.) (2010) Tackling wicked problems through the transdisciplinary imagination. London: Earthscan.

Bucher, T. (2017) The algorithmic imaginary: exploring the ordinary effects of Facebook algorithms. Information, Communication \& Society, 20(1): 30-44.

Callon, M., P. Lascoumes en Y. Barthe (2009) Acting in an uncertain world: an essay on technical democracy. Cambridge: MIT Press.

Coady, D. (red.) (2006) Conspiracy Theories: The Philosophical Debate. Aldershot: Ashgate.

Cohen, S. (2011[1972]) Folk Devils and Moral Panics. London: Routledge.

Collins, H. en R. Evans (2008) Rethinking expertise. Chicago: University of Chicago Press.

Collins, H., R. Evans en M. Weinel (2017) STS as science or politics?. Social Studies of Science, 47 (4): 580-586.

Diakopoulos, N. (2016) Accountability in algorithmic decision making. Communications of the $A C M, 59(2): 56-62$.

Dietvorst, B.J., J.P. Simmons en C. Massey (2015) Algorithm aversion: People erroneously avoid algorithms after seeing them err. Journal of Experimental Psychology: General, 144(1): 114-126.

Dijck, J. van, T. Poell en M.D. Waal (2016) De platformsamenleving: strijd om publieke waarden in een online wereld. Amsterdam: Amsterdam University Press.

Dijstelbloem, H. (2008) Politiek vernieuwen: op zoek naar publiek in de technologische samenleving. Amsterdam: Van Gennep.

Dojcinovic, S. (2017) Hey, Mark Zuckerberg: My Democracy Isn't Your Laboratory, The New York Times, 15 november. Verkregen op 12 december 2017, https://www.nytimes.com/2017/11/15/ opinion/serbia-facebook-explore-feed.html.

Elias, N. en J.L. Scotson (1994) The Established and the Outsiders. London: Sage.

Epstein, S. (1996) Impure Science: AIDS, Activism, and the Politics of Knowledge. Berkeley: University of California Press.

Eslami, M., A. Rickman, K. Vaccaro, A. Aleyasen, A. Vuong, K. Karahalios en C. Sandvig (2015) I always assumed that I wasn't really that close to [her]: Reasoning about Invisible Algorithms in News Feeds. Proceedings of the 33rd Annual ACM Conference on Human Factors in Computing Systems, 153-162.

Foer, F. (2017) World Without Mind: The Existential Threat of Big Tech. London: Penguin.

Fuller, S. (2008) Dissent over descent: intelligent design's challenge to Darwinism. Thriplow: Icon.

Fuller, S. (2016a) Embrace the inner fox: Post-truth as the STS symmetry principle universalized. Social Epistemology Review \& Reply Collective. Verkregen op 25 januari 2018, https://social- 
epistemology.com/2016/12/25/embrace-the-inner-fox-post-truth-as-the-sts-symmetry-principle-universalized-steve-fuller/\#comments.

Fuller, S. (2016b) Science has always been a bit 'post-truth'. The Guardian, 15 december.

Fuller, S. (2017) Is STS all talk and no walk? EASST Review, 36(1), https://easst.net/article/is-sts-alltalk-and-no-walk.

Gane, C. (2017) How "Manipulation Armies" Are Undermining Democracies. Psychology Today. Verkregen op 12 december 2017, https://www.psychologytoday.com/blog/side-effects/201711/ how-manipulation-armies-are-undermining-democracies.

Gauchat, G. (2011) The Cultural Authority of Science: Public Trust and Acceptance of Organized Science. Public Understanding of Science, 20(6): 751-770.

Gieryn, T.F. (1999) Cultural Boundaries of Science: Credibility on the Line. Chicago: University of Chicago Press.

Goble, P. (2014) Lies, damned lies and Russian disinformation. Eurasia Daily Monitor, 13.

Goffman, E. (1963) Stigma: Notes on the Management of Spoiled Identities. Englewood Cliffs: Prentice-Hall.

Graves, L. (2016) Deciding what's true: The rise of political fact-checking in American journalism. New York: Columbia University Press.

Hackett, E.J., O. Amsterdamska, M. Lynch en J. Wajcman (2008) The handbook of science and technology studies. Cambridge: MIT Press.

Harambam, J. (2017) The truth is out there: Conspiracy culture in an age of epistemic instability. PhD dissertation, Erasmus University Rotterdam.

Harambam, J. en S. Aupers (2015) Contesting epistemic authority: Conspiracy theories on the boundaries of science. Public Understanding of Science, 24(4): 466-480.

Harambam, J. en S. Aupers (2017) 'I Am Not a Conspiracy Theorist': Relational Identifications in the Dutch Conspiracy Milieu. Cultural Sociology, 11(1): 113-129.

Haraway, D. (1991) Simians, Cyborgs, and Women: The Reinvention of Nature. New York: Routledge.

Helberger, N., K. Karppinen en L. D'Acunto (2018) Exposure diversity as a design principle for recommender systems. Information, Communication \& Society, 21(2): 191-207.

Hochschild, A.R. (2016) Strangers in their own land: Anger and mourning on the American right. New York: The New Press.

Holst, C. en A. Molander (2014) Epistemic democracy and the accountability of experts. Expertise and democracy, 13-35.

Husting, G. en M. Orr (2007) Dangerous Machinery: "Conspiracy Theorist" as a Transpersonal Strategy of Exclusion. Symbolic Interaction, 30(2): 127-150.

Inbar, Y. en J. Lammers (2012) Political diversity in social and personality psychology. Perspectives on Psychological Science, 7(5): 496-503.

Jamieson, K.H. en J.N. Cappella (2008) Echo chamber: Rush Limbaugh and the conservative media establishment. Oxford: Oxford University Press.

Jenkins, H. (2006) Convergence Culture: Where Old and New Media Collide. New York: New York University Press.

Kelly S., M. Truong, A. Shahbaz, M. Earp en J. White (2017) Freedom of the Net. Manipulating Social Media to Undermine Democracy. Washington: Freedom House Report.

Kemmers, R. (2017) Channelling discontent? Non-voters, populist party voters, and their meaningful political agency. European Journal of Cultural and Political Sociology, 4(4): 381-406.

Kolko, J. (2012) Wicked Problems: Problems Worth Solving: A Handbook \& A Call to Action, Austin: $\mathrm{AC}_{4} \mathrm{D}$.

Kovach, B. (2010) Blur: How to Know What's True in the Age of Information Overload. New York: Bloomsbury. 
Latour, B. (1987) Science in action: How to follow scientists and engineers through society. Cambridge: Harvard University Press.

Latour, B. (2004) Politics of nature. Cambridge: Harvard University Press.

Latour, B. en P. Weibel (2005) Making things public: atmospheres of democracy. Cambridge: MIT Press.

Lukassen, S. (2015) Avondland en Identiteit. Utrecht: Aspect.

Lynch, M. (1997) Scientific practice and ordinary action: Ethnomethodology and social studies of science. Cambridge: Cambridge University Press.

Lynch, M. (2017) STS, symmetry and post-truth. Social Studies of Science, 47(4): 593-599.

Maasen, S. en P. Weingart (red.) (2006) Democratization of expertise? Exploring novel forms of scientific advice in political decision-making. Sociology of the Sciences Yearbook.

Martin, B. (red.) (1996) Confronting the Experts. Albany: State University of New York Press.

Martin, B. (2017) Vaccination Panic in Australia, forthcoming.

Marres, N. (2012) Material participation: technology, the environment and everyday publics. Basingstoke: Palgrave Macmillan.

M'Charek, A., I. van Oorschot, R. Benschop en J. Harambam (red.) (2015) Monsters in de sociologie: de wondere wereld van ANT. Amsterdam: Boom/Lemma.

Mepschen, P. (2016) Everyday autochthony: Difference, discontent and the politics of home in Amsterdam. PhD dissertation, Universiteit van Amsterdam.

Misztal, B. (2013) Trust in Modern Societies: The Search for the Bases of Social Order. Malden: Wiley.

Mol, A. (2002) The body multiple: Ontology in medical practice. Durham: Duke University Press.

Morozov, E. (2011) The net delusion: How not to liberate the world. London: Penguin.

Mortimer, K. (2017) Understanding Conspiracy Online: Social Media and the Spread of Suspicious Thinking. Dalhousie Journal of Interdisciplinary Management, 13(1): 1-16.

Mouffe, C. (2000) The Democratic Paradox. New York: Verso.

Moy, P. en M. Pfau (200o) With Malice Toward All? The Media and Public Confidence in Democratic Institutions. Westport: Greenwood.

Nussbaum, M.C. (2016) Not for Profit: Why Democracy Needs the Humanities. Princeton: Princeton University Press.

Nye, J.S. (2004) Soft power: The means to success in world politics. New York: Public affairs.

Pariser, E. (2011) The filter bubble: What the Internet is hiding from you. London: Penguin.

Powers, E. (2017) My News Feed is Filtered? Awareness of news personalization among college students. Digital Journalism, 5(10): 1-21.

Rabeharisoa V., T. Moreira en M. Akrich (2014) Evidence-based activism: Patients', users' and activists' groups in knowledge society. BioSocieties, 9(2): 111-128.

Rittel, H.W. en M.M. Webber (1973) Dilemmas in a general theory of planning. Policy sciences, 4 (2): 155-169.

Shapin, S. (1994) A social history of truth: Civility and science in seventeenth-century England. Chicago: University of Chicago Press.

Shapiro, A.L. (1999) The control revolution: How the Internet is putting individuals in charge and changing the world we know. New York: Perseus Books.

Shenk, D. (1998) Data smog: Surviving the information glut. San Francisco: Harper.

Sismondo, S. (2004) An introduction to science and technology studies. London: Blackwell.

Sismondo, S. (2017) Post-truth? Social Studies of Science, 47(4): 593-599.

Spector, M. en J.I. Kitsuse (1977) Constructing Social Problems. Menlo Park: Cummings.

Sunstein, C. (2017) \#Republic: Divided Democracy in the Age of Social Media. Princeton: Princeton University Press.

Tufekci, Z. (2017a) Facebook Said Its Algorithms Do Help Form Echo Chambers. And the Tech 
Press Missed It. Huffington Post. Verkregen op 12 december 2017, https://www.huffingtonpost.com/zeynep-tufekci/facebook-algorithm-echo-chambers_b_7259916.html.

Tufekci, Z. (2017b) Twitter and Tear Gas: The Power and Fragility of Networked Protest. New Haven: Yale University Press.

Uscinski, J.E. en R.W. Butler (2013) The epistemology of fact checking. Critical Review, 25(2): 162180.

Weinberger, D. (2007) Everything Is Miscellaneous: The Power of the New Digital Disorder. New York: Henry Holt.

\section{Over de auteur}

Jaron Harambam is socioloog en als postdoc werkzaam bij het Instituut voor Informatierecht (IViR, Universiteit van Amsterdam), waar hij binnen het multidisciplinaire Fair News Project onderzoek doet naar algoritmes in nieuwsmedia. Hij is onlangs aan de Erasmus Universiteit Rotterdam cum laude gepromoveerd op een etnografisch proefschrift over de cultuur van complotdenken in Nederland, getiteld The Truth is Out There. Conspiracy Culture in an Age of Epistemic Instability. Hij is vast redactielid van Sociologie, en heeft in deze rol in 2014 een themanummer over actor-netwerk theorie geredigeerd. In 2015 was hij als visiting fellow verbonden aan het Science in Human Culture program van de Northwestern University nabij Chicago (VS). Hij heeft gepubliceerd over complotdenken, digitale cultuur en online-spelwerelden in internationale peer-reviewed tijdschriften zoals Cultural Sociology, Public Understanding of Science, Information, Communication and Society en het European Journal of Cultural Studies. Jaron is voornamelijk geïnteresseerd in sociologische fenomenen op het snijvlak van wetenschap, religie, populaire cultuur en media.

E-mail: jaron.harambam@gmail.com 